\title{
Matching mechanism of operating mode and profiting mode to interorganizational information systems
}

\author{
Zhuang Wei-Qing \\ School of management, Fujian University of Technology, China \\ zmakio@aliyun.com
}

Keywords: interorganizational information systems; operating mode; profiting mode; matching mechanism

\begin{abstract}
The working of this paper focuses on the matching relationship of operating mode and profiting mode to interorganizational information systems(IOS) to help to make a decision on how to choose or build an IOS to IOS' users and provider. Firstly, this paper builds a theoretical matching model on operating mode and profiting mode to IOS; and then examines the relationship of factors of operating and profiting in practice to figure out the matching characteristics; lastly, prompts to a expected dynamic optimal profit model to reflect the matching mechanism.
\end{abstract}

\section{Introduction}

With the success of Alibaba IPO in U.S. history, the e-commerce mode of Alibaba becomes a heated discussion again, including the operating mode and profiting mode of e-commerce. However, there are a large number of questions we still confuse as follows.

(1) Interorganizational information systems(IOS) are increasingly involved in economic management activities, and a few of them, including users and provider generate tremendous value to firm, but a majority of them don't.

(2) It is uncertain to the way of construction and profiting points of IOS to most firms.

(3) It is significantly different to IOS' profit under the same operating mode to firm.

(4) How to survive to these homogeneity IOS.

(5) IOS' users can also reap huge gains like the provider.

This paper focuses on the matching mechanism of operating mode and profiting mode to interorganizational information systems(IOS), which helps to make a decision on how to choose or build an IOS to IOS' users and provider. Hence, it can explain the relationship between coordination and performance of IOS.

There are separated researches on coordination and performance of IOS, and lack of the mechanism to evaluate the two relationship. This paper will probe into the matching mechanism of operating mode and profiting mode to IOS, which connects the coordination and performance of IOS. It is to determine the mode to maximize its profit matching the different modes of operation, extending the research of coordination and performance of IOS. Matching mechanism is not only a game issue in examining IOS' users and provider how to choose and build an operating mode, also a game problem on choose to build a profiting mode. This paper will deepen (Jeffrey O. Kephart et al., 2000[1]; Peter C.Fishburn \& Andrew M.Odlyzko, 2000[2]; Zhen Liu, Cathy Xia \& Laura Wynter, 2002[3]; Srinivasan Jagannathan et al., 2004[4]; Hai Yang \& Hai-Jun Huang, 2004[5]; Ahmed Patel \& Muhammad J.Khan, 2007[6]; Subodha Kumar et al., 2009[7]; Tieming Liu et al., 2010[8]; Adnéne Hajji et al., 2012[9]; W.Q Zhuang \& Z.Y Liu, 2012[10]; Z.Y Liu \& W.Q Zhuang, 2013[11]; W.Q Zhuang \& Z.Y Liu, 2013[12]) these studies.

\section{Theoretical model}

Operating mode of IOS. The operating mode of IOS can be classified as resource pooling IOS mode, complementary cooperation IOS mode, operational cooperation IOS mode, and operational coordination IOS mode, consisting of two dimensions-role linkage and system support level from Ilyoo B. Hong(2002)[13] shown in Figure 1. It is significant difference of profit under these four 
modes of IOS' operating depending on different services(data, information) based on different dimension, particularly adding these characteristics of market structure, network characteristics, structure cost(W.Q Zhuang \& Z.Y Liu, 2013[12]), transaction cost, the size of IOS, behavior of IOS’ provider and user, subsidy policy can be further differentiated.

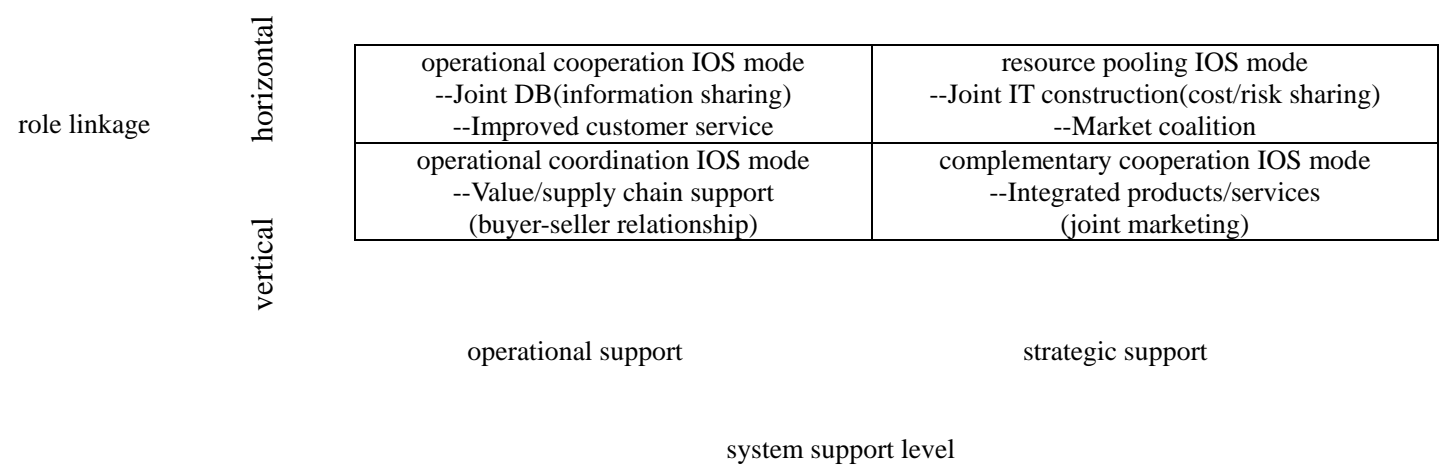

Fig. 1. A classification for operating mode of IOS.

Matching model of operating mode and profiting mode to IOS. It can be defined by role linkage and system support level to operating mode of IOS, for example, asking for coalition and supply chain support is dramatically different for coalition and customer service. Why do or should IOS' users or provider choose or build this one operating mode that depends on the profit should bring about under the condition of risk preference, behavior, market structure and network externality, etc. And IOS' profiting mode consisted by pricing, participant number, subsidy level, transaction cost and structure cost connects and matches with IOS' operating mode by means of intervening mechanism that affected by users or provider's risk preference and behavior, market structure, network externality, showing as Figure 2.

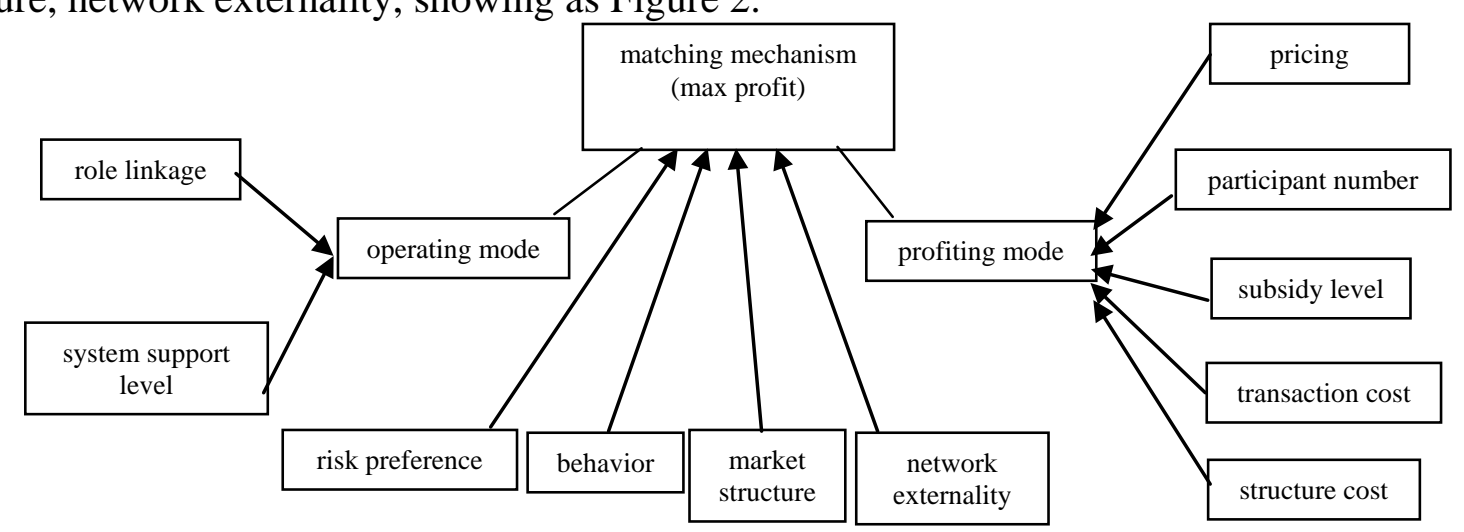

Fig. 2. Matching model of operating mode and profiting mode to IOS.

\section{Matching mechanism of operating mode and profiting mode to IOS}

In order to explain well the matching mechanism of operating mode and profiting mode to IOS, this paper does a survey \& data gathering on several e-commerce platform(shown in Table 1) that influenced factors of operating mode how to change with the dynamic changing of profiting mode factors, pricing, participant number, subsidy level, transaction cost, structure cost. And then builds econometric model to measure the relation of two dependent variables RoleL and SysSupL with independent variables, pricing, participant number, subsidy level, transaction cost, structure cost, etc. from profiting mode factors. It can be shown in formula (1),(2) that appropriate coupling in dependent variables with independent variables gets through the dynamic observed data over time. For example, the pricing level at $t_{i}$ time should be matched which kind of role linkage or system support level to obtain the maximized profit, or what pricing level should be set to match a given role linkage or system support level. This is matching mechanism. 
Table 1Case of empirical research

\begin{tabular}{|l|c|}
\hline \multicolumn{1}{|c|}{ operating mode of IOS } & e-commerce platform \\
\hline resource pooling IOS mode & MeiTuan.com \\
\hline complementary cooperation IOS mode & TaoBao.com \\
\hline operational cooperation IOS mode & GanJi.com \\
\hline operational coordination IOS mode & JD.com \\
\hline
\end{tabular}

$$
\begin{array}{r}
\text { RoleL }=b_{0}+b_{1} \cdot \text { Pricing }+b_{2} \cdot \operatorname{ParN}+b_{3} \cdot \operatorname{SubL}+b_{4} \cdot \operatorname{TraC}+b_{5} \cdot \operatorname{Str} C+b_{6} \cdot \operatorname{Str} C \times \operatorname{Ris} P+\varepsilon \\
\text { SysSupL }=b_{0}+b_{1} \cdot \text { Pricing }+b_{2} \cdot \operatorname{ParN}+b_{3} \cdot \operatorname{SubL}+b_{4} \cdot \operatorname{Tra} C+b_{5} \cdot \operatorname{Str} C+b_{6} \cdot \operatorname{Str} C \times \operatorname{Ris} P+\varepsilon
\end{array}
$$

These variables' notation describe as the Table 2.

Table 2Description of variables' notation

\begin{tabular}{|c|c|}
\hline variables & definition \\
\hline RoleL & role linkage \\
\hline SysSupL & system support level \\
\hline Pricing & service pricing \\
\hline ParN & participant number \\
\hline SubL & subsidy level \\
\hline TraC & transaction cost \\
\hline StrC & structure cost \\
\hline Strc $\times$ RisP & measuring users or provider's risk preference \\
\hline
\end{tabular}

As a result of regression on model (1) and (2) shows significant correlativity of all independent variables and dependent variables to four kinds of operating mode of IOS. However, there are obvious difference in the role of profiting mode factors contributing to RoleL and SysSupL separately, shown in Table 3.

\begin{tabular}{|c|c|c|c|c|c|c|c|c|}
\hline & $\begin{array}{c}\text { operating } \\
\text { mode of IOS }\end{array}$ & $\mathrm{C}$ & Pricing & ParN & SubL & TraC & StrC & $\begin{array}{c}\text { Strc } \times \text { Ris } \\
\mathbf{P}\end{array}$ \\
\hline \multirow{4}{*}{ RoleL } & $\begin{array}{l}\text { resource } \\
\text { pooling IOS } \\
\text { mode }\end{array}$ & $\begin{array}{c}-10.6008 * \\
* \\
(-11.0566 \\
)\end{array}$ & $\begin{array}{c}2.1972 * \\
* \\
(4.3116)\end{array}$ & $\begin{array}{c}0.0088^{* *} \\
(3.1492)\end{array}$ & $\begin{array}{c}25.6216 * \\
* \\
(35.5430 \\
)\end{array}$ & $\begin{array}{c}0.1475 * \\
* \\
(2.2116)\end{array}$ & $\begin{array}{c}0.0215 * \\
* \\
(2.1959)\end{array}$ & $\begin{array}{c}0.0181 * * \\
(2.1163)\end{array}$ \\
\hline & $\begin{array}{l}\text { complementa } \\
\text { ry } \\
\text { cooperation } \\
\text { IOS mode }\end{array}$ & $\begin{array}{c}-14.3875 * \\
* \\
(-7.1253)\end{array}$ & $\begin{array}{c}3.4164 * \\
* \\
(7.0980)\end{array}$ & $\begin{array}{l}0.0042^{* *} \\
(2.5461)\end{array}$ & $\begin{array}{c}15.4802 * \\
* \\
(21.0327 \\
)\end{array}$ & $\begin{array}{c}0.1166 * \\
* \\
(4.0125)\end{array}$ & $\begin{array}{c}0.1065 * \\
* \\
(3.1004)\end{array}$ & $\begin{array}{c}0.0903 * * \\
(2.7321)\end{array}$ \\
\hline & $\begin{array}{l}\text { operational } \\
\text { cooperation } \\
\text { IOS mode }\end{array}$ & $\begin{array}{c}2.7618^{* *} \\
(5.1200)\end{array}$ & $\begin{array}{c}1.6901^{*} \\
* \\
(2.0155)\end{array}$ & $\begin{array}{l}0.0073^{* *} \\
(2.3032)\end{array}$ & $\begin{array}{c}20.7009 * \\
* \\
(21.9012 \\
)\end{array}$ & $\begin{array}{c}0.2778 * \\
* \\
(4.6120)\end{array}$ & $\begin{array}{c}0.0132 * \\
* \\
(3.3466)\end{array}$ & $\begin{array}{c}0.0104^{* *} \\
(2.1079)\end{array}$ \\
\hline & $\begin{array}{l}\text { operational } \\
\text { coordination } \\
\text { IOS mode }\end{array}$ & $\begin{array}{c}24.1120 * \\
* \\
(45.1845)\end{array}$ & $\begin{array}{c}2.3771 * \\
* \\
(8.6028)\end{array}$ & $\begin{array}{c}0.01206 * \\
* \\
(12.3201 \\
)\end{array}$ & $\begin{array}{c}3.6978 * * \\
(5.9505)\end{array}$ & $\begin{array}{c}0.2013 * \\
* \\
(2.1089)\end{array}$ & $\begin{array}{c}0.0695 * \\
* \\
(2.3107)\end{array}$ & $\begin{array}{c}0.0323 * * \\
(3.3343)\end{array}$ \\
\hline \multirow{2}{*}{$\begin{array}{c}\text { SysSup } \\
\text { L }\end{array}$} & $\begin{array}{l}\text { resource } \\
\text { pooling IOS } \\
\text { mode }\end{array}$ & $\begin{array}{c}-26.2392 * \\
* \\
(-3.2197)\end{array}$ & $\begin{array}{c}4.7213^{*} \\
* \\
(3.1408)\end{array}$ & $\begin{array}{c}0.0213^{* *} \\
(3.4081)\end{array}$ & $\begin{array}{c}68.7355^{*} \\
* \\
(2.7931)\end{array}$ & $\begin{array}{c}0.3747 * \\
* \\
(3.7897)\end{array}$ & $\begin{array}{c}-0.0195 * \\
* \\
(-2.2184 \\
)\end{array}$ & $\begin{array}{c}0.0032 * * \\
(2.4635)\end{array}$ \\
\hline & $\begin{array}{l}\text { complementa } \\
\text { ry } \\
\text { cooperation }\end{array}$ & $\begin{array}{c}-86.1822 * \\
* \\
(-43.2232\end{array}$ & $\begin{array}{c}5.9971^{*} \\
* \\
(4.2377)\end{array}$ & $\begin{array}{c}0.0133^{* *} \\
(2.1122)\end{array}$ & $\begin{array}{c}56.2445 * \\
* \\
(2.0997)\end{array}$ & $\begin{array}{c}0.1677 * \\
* \\
(2.7211)\end{array}$ & $\begin{array}{c}-0.1307 * \\
* \\
(-2.3354\end{array}$ & $\begin{array}{c}0.0159 * * \\
(2.0115)\end{array}$ \\
\hline
\end{tabular}

Table 3Industry matching supply chain FIOS topology structure 


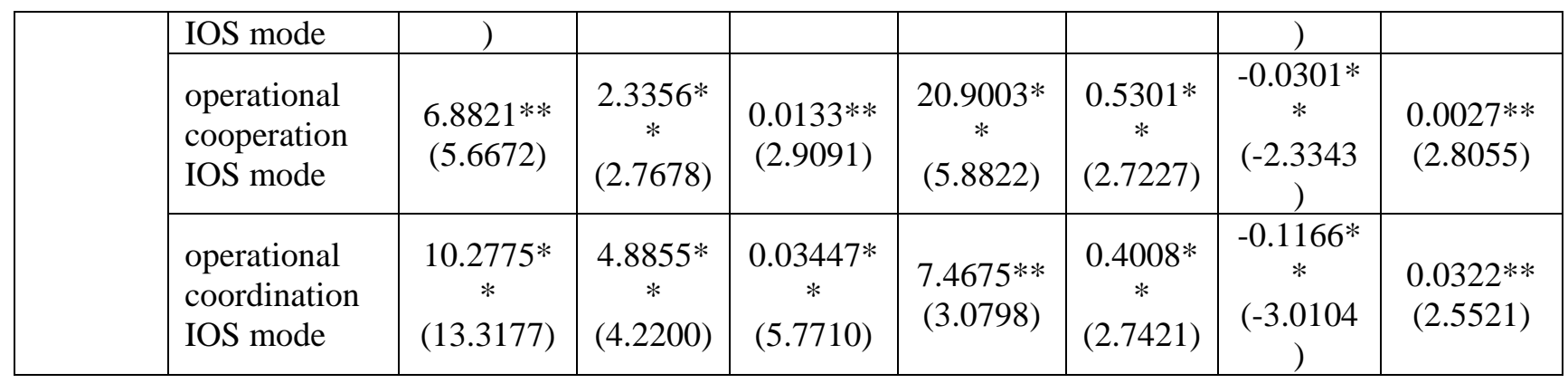

According to the coefficient of relationship of independent variables, pricing, participant number, subsidy level, transaction cost, structure cost and dependent variables, role linkage, system support level, it can be further prompted to a dynamic optimal profit model to reflect the matching mechanism of operating mode and profiting mode to IOS(showing as formula (3)).

$$
\begin{aligned}
& \text { MAX }\left(\sum_{i}^{\text {ParN } \left._{i} \text { Pricing }_{i}-\text { SubL }- \text { TraC }- \text { StrC }\right)}\right. \\
& \text { S.t. }\left\{\begin{array}{l}
\text { RoleL } \in\left(f_{-}\left(b_{1}, b_{2}, b_{3}, b_{4}, b_{5}, b_{6}\right), f_{+}\left(b_{1}, b_{2}, b_{3}, b_{4}, b_{5}, b_{6}\right),\right) \\
\text { SysSupL } \in\left(f_{-}\left(b_{1}, b_{2}, b_{3}, b_{4}, b_{5}, b_{6}\right), f_{+}\left(b_{1}, b_{2}, b_{3}, b_{4}, b_{5}, b_{6}\right),\right)
\end{array}\right.
\end{aligned}
$$

\section{Conclusion}

This paper contributes to the matching mechanism of operating mode and profiting mode to IOS and testifies the relationship of them in practice in order to help to make a decision on how to choose or build an IOS to IOS' users and provider. According to the results of empirical research, it can be seen that these independent variables of pricing, participant number, subsidy level, transaction cost and structure cost are different impact on the role of linkage and system support level to decide to choose one king of operating modes. Also, the results can be used deeply to design a dynamic profit model to reflect the matching mechanism theory.

In a word, the further research in application about matching mechanism of operating mode and profiting mode to IOS and the dynamic optimal profit model under the matching mechanism will be paid close attention.

\section{Acknowledgements}

This work was financially supported by the humanities and social science research project from Ministry of Education, China, (Youth Fund)(ID: 14YJC630224).

\section{References}

[1] Jeffrey O. Kephart, James E. Hanson, and Amy R. Greenwald: Dynamic Pricing by Software Agents, Computer Networks, 32(6) (2000), p. 731-752

[2] Peter C.Fishburn, and Andrew M.Odlyzko: Dynamic Behavior of Differential Pricing and Quality of Service Options for the Internet, Decision Support Systems, 28(1-2) (2000), p. 123-136

[3] Zhen Liu, Cathy Xia, and Laura Wynter: Pricing Information Services in a Competitive Market: Avoiding Price Wars, tech. rep. Nº4679 (THÈME 4), 12 (2002), p. 1-19

[4] Srinivasan Jagannathan, and Kevin C. Almeroth: A Dynamic Pricing Scheme for E-content at Multiple Levels-of-Service, Computer Communications, 27(4) (2004), p. 374-385

[5] Hai Yang, and Hai-Jun Huang: Modeling User Adoption of Advanced Traveler Information Systems: A Control Theoretic Approach for Optimal Endogenous Growth, Transportation Research Part C, 12(3-4) (2004), P. 193-207 
[6] Ahmed Patel, and Muhammad J.Khan: Evaluation of Service Management Algorithms in a Distributed Web Search System, Computer Standards \& Interfaces, 29(2) (2007), p. 152-160

[7] Subodha Kumar, and Suresh P. Sethi: Dynamic Pricing and Advertising for Web Content Providers, European Journal of Operational Research, 197(3) (2009), p. 924-944

[8] Tieming Liu, Chinnatat Methapatara, and Laura Wynter: Revenue Management Model for On-demand IT Services, European Journal of Operational Research, 207(1) (2010), p. 401-408.

[9] Adnéne Hajji, Robert Pellerin, Pierre-Majorique Léger, Ali Gharbi, and Gilbert Babin: Dynamic Pricing Models for ERP Systems Under Network Externality, Int. J. Production Economics, 135(2) (2012), p. 708-715

[10] Zhuang Wei-Qing, and Liu Zhen-Yu: Build structure of fractal interorganizational information systems and optimize supply chain structure, Advanced Materials Research, 468-471 (2012), p. 268-276

[11] Zhenyu LIU, and Weiqing ZHUANG: Governance of Global Supply Chains Vulnerability by Business-Based IOP, Journal of Systems Science and Systems Engineering, 22(1) (2013), p. 1-20

[12] Zhuang Weiqing, and Liu Zhenyu: Research on the Fitness with Industry Type and Interorganizational Information Systems' Topological Structure Based on Structure Cost, Operations Research and Management Science, 22(6) (2013), p. 215-224(in Chinese)

[13]Ilyoo B. Hong: A new framework for interorganizational systems based on the linkage of participants’ roles, Information \& Management, 39(4) (2002), p. 261-270 